\title{
A CASE OF SUBCLAVIAN ARTERY STENOSIS AND UNILATERAL FINGER CLUBBING
}

\author{
Captain H. N. WHITFIELD, M.A., M.B., F.R.C.S., R.A.M.C. \\ The Queen Alexandra Military Hospital, Millbank *
}

\begin{abstract}
SUMMARY: A case of subclavian steal syndrome in association with unilateral finger clubbing and severe pain in the fingers is described. These associations to my knowledge have not been described previously. The pathology of the excised segment of vessel supports the suggestion of trauma as the aetiology.
\end{abstract}

\section{Introduction}

Subclavian artery stenosis with subclavian steal syndrome was first described by Contorni (1960). Since then many cases have appeared in the literature, and the pathophysiology investigated both in animal models and in patients (Reivich, et al 1961, Parrott 1964). The case reported below was associated with some previously unrecorded features.

\section{Case history}

A 31 year old army officer, N.S., presented in December 1967 with severe, rightsided frontal headaches, associated with nausea and photophobia. A diagnosis of migraine was made, but the headaches were unrelieved by ergot. In August 1968 the patient first noticed episodes of pain in the ring, middle and index fingers of his left hand. During attacks the fingers became swollen and pink and the pain was severe enough to wake him at night.

The headaches and the pain in the fingers could occur together or independently, and neither was provoked by exercise. The attacks continued over the subsequent two years and became more frequent and more severe. From July 1969 they began to be associated with vomiting, vertigo and syncope, and the affected fingers were permanently swollen.

The only significant past history was a road traffic accident in 1959 in which the patient was knocked unconscious for twenty minutes. There was no bone injury, but extensive contusions of the left side of the head and neck and shoulder region.

In July 1970, after a severe attack of vertigo, he was admitted to hospital. On examination the index, middle and ring fingers of the left hand were clubbed (Fig. 1). The blood pressure in the right arm was $150 / 90 \mathrm{mmHg}$ and in the left arm $110 / 85 \mathrm{mmHg}$. A Grade III systolic bruit was audible above the middle of the left clavicle. Physical examination, including examination of the central nervous system, was otherwise unremarkable.

The haemoglobin was $16.3 \mathrm{~g} / 100 \mathrm{ml}$, E.S.R. $1 \mathrm{~mm}$ in the first hour (Westergren) and total plasma proteins $7.2 \mathrm{~g} / 100 \mathrm{ml}$ with a normal electrophoretic pattern. The Wasserman Reaction and Kahn Test were both negative. The fasting cholesterol and triglyceride levels were normal $(280 \mathrm{mg} / 100 \mathrm{ml}$ and $112 \mathrm{mg} / 100 \mathrm{ml}$ respectively). No antinuclear factor was detected. 


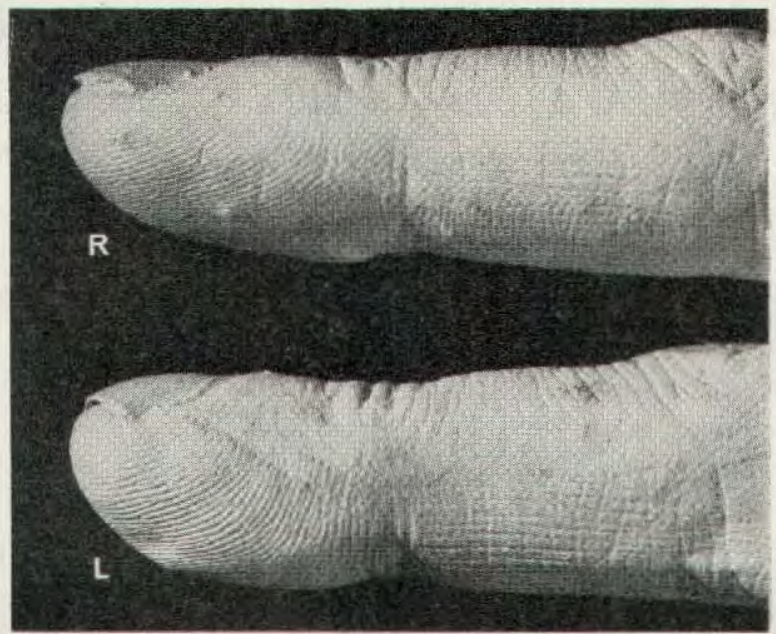

Fig. 1. Casts of index fingers, showing swelling of terminal phalanx and decreased hyponychial angle of left index finger, July 1970.

Chest X.-ray and X-ray of the hand were normal, and there was no radiographic evidence of a cervical rib. Electrocardiogram. electro-encephalogram and ophthalmodynometry were all within normal limits.

An arch aortogram demonstrated stenosis of the first part of the left subclavian artery (Fig. 2). Retrograde flow down the left vertebral artery was not seen. A brachial arteriogram demonstrated a pressure drop of $30 \mathrm{mmHg}$ across the stenosis.

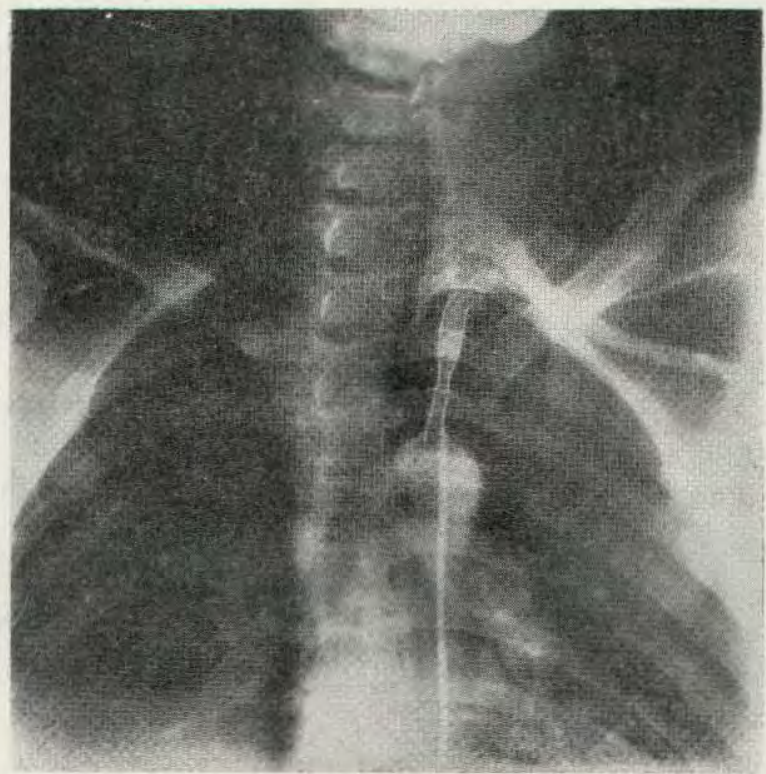

Fig. 2. Angiogram showing stenosis of first part of left subclavian artery. 


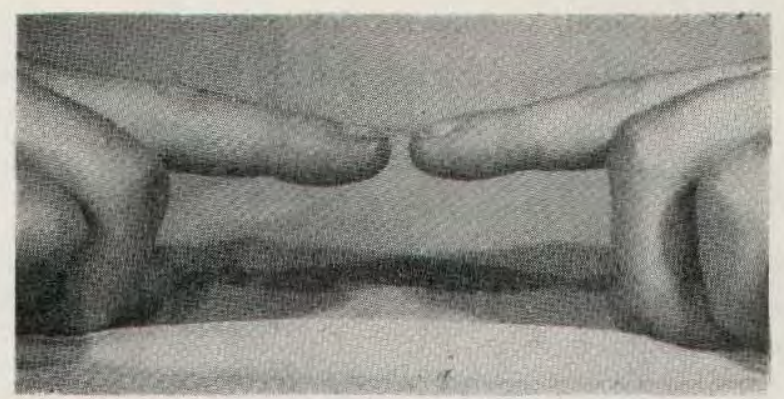

Fig, 3. Index fingers 10 weeks after sympathectomy.

On 14 August 1970 the left subclavian artery was exposed through a standard left thoracotomy. The proximal end of the artery showed increased fixation to mediastinal tissues, and palpation revealed that the artery was largely obliterated from its origin to within one centimetre of its vertebral branch. The stenosed segment of artery was excised and replaced with an $8 \mathrm{~mm}$ woven dacron prosthesis. The graft thrombosed later the same day, and surgery was again undertaken. Despite careful resuturing of the graft after evacuating clot, the graft once more became occluded. In an attempt to minimise further problems, anticoagulent therapy was instituted with heparin after removal of clot on the second occasion. It is well recognised that anticoagulant treatment with a graft inside the chest is potentially dangerous, but the decision was considered justified in an attempt to improve, however marginally, the prospect of persistent graft patency.

The resected segments of vessel showed no significant atherosclerosis, the appearances being suggestive of organised thrombotic occlusion. The lumen was occluded by a mass of loose, oedematous vascular fibrous tissue with an endothelial covering.

Post-operatively oral anticoagulent therapy was substituted for heparin over the first forty-eight hours. The blood pressure in the left arm was maintained at 130/80 $\mathrm{mmHg}$ and in the right arm remained $150 / 90$. However, the pain in the fingers of the left hand remained and was more severe than pre-operatively and was associated with patchy cyanosis of the whole hand, hyperhidrosis and hyperaesthesia of the finger tips and increased clubbing. A left stellate ganglion block was performed using $10 \mathrm{ml} 0.5$ per cent Lignocaine, which resulted in complete temporary relief of the pain.

Forearm blood flow measurements by strain gauge plethysmography at that time revealed no significant difference between the two sides, eitrer at rest or during the phase of reactive hyperaemia following five minutes arterial occlusion. Finger plethysmography revealed markedly increased pulse and flow in the left thumb and left index finger, more indicative of a primary nervous rather than a vascular lesion.

Because the pain in the hand was severe and unrelieved by non-opiate analgesics, and in view of the relief afforded by the stellate ganglion block, a left cervical sympathectomy was performed on 15 December 1970. There was a great deal of fibrosis as a result of the previous operations and the sympathectomy which was carried out was not considered to be complete.

Immediately post-operatively the patient was pain free. Anti-coagulant therapy was withdrawn after three months. Six months post-operatively the patient remains pain free, the blood pressure in the left arm is maintained at $130 / 80 \mathrm{mmHg}$, and the clubbing of the fingers of the left hand has partially regressed (Fig. 3). 


\section{Discussion}

Although the patient did not exhibit all the features of the subclavian steal syndrome it seemed most likely that this was the cause of his disabling attacks of vertigo and headaches. Restoration of normal blood flow through the first part of the left subclavian artery successfully abolished these symptoms.

In a review of 110 cases of the subclavian steal syndrome Killen, et al (1966) found that the usual aetiology was arteriosclerosis, though in a small percentage the lesion was thought to be congenital in origin.

The pathology in this case indicates that trauma was the most likely aetiology. No previous case of trauma without bony injury giving rise to a subclavian steal syndrome has been reported.

The cause of the finger clubbing was not clear. Bilateral clubbing of the fingers occurs in association with a number of different diseases (Mendelowitz 1942), though the mechanism is disputed and different hypotheses have been advanced (Cudkowicz and Armstrong 1953, Flavell, 1956, Hall 1959, Mauer 1947, Wilson 1952).

Unilateral finger clubbing is rare but has been reported in association with aneurysms of the arch of the aorta, and of the innominate, subclavian and axillary arteries (Mendelowitz 1942, Cross and Wilson 1950, Wilson 1952). Eisinger (1968) reported a case of unilateral finger clubbing in two fingers which had been the site of previous trauma, though his patient also had bronchiectasis and dextrocardia. Wilson (1952) described a case of bilateral finger clubbing attributed to recurrent pulmonary infections, in which the finger clubbing regressed on one side following ligation of the ipsilateral subclavian artery during operation for excision of the first rib.

Rarer causes of unilateral finger clubbing which have been reported include dislocation of the shoulder, carcinoma of the apex of the lung and phlebectasia (Rodgers 1941). Turner and his colleagues (1937) also drew attention to the increased peripheral blood flow in cases of acquired finger clubbing.

It is of interest that the clubbing in the patient was made worse by restoration of normal blood flow to the arm.

The origin of the pain in the fingers is also obscure. The clinical picture and response to sympathectomy resembled causalgia secondary to closed injury of the brachial plexus, but the long time interval ( 9 years) between the trauma and the onset of symptoms is against this diagnosis (Barnes 1954).

Mendolowitz (1942) states that severe burning pain may be associated with clubbing and precede X-ray changes, but although unilateral vagotomy is well recognised to relieve the pain of hypertrophic osteoarthropathy (Flavell 1956) this does not explain why partial sympathectomy should have had the same result. Claudication pain may occur in the subclavian steal syndrome but is always provoked by exercise (Killen, et al 1966). The pain in the fingers in our patient was neither claudication in type nor precipitated by exercise.

\section{Acknowledgements}

The author wishes to thank Dr. D. M. F. Batty, Consultant Physician to the Royal Infirmary, Edinburgh for permission to study the patient while under his care, and 
Mr. A. R. Logan and Professor Sir Michael Woodruff for the part they played in the management of this patient. My thanks are also due to Dr. E. Housley and Dr. D. N. Williams who were most helpful during the -preparation of the manuscript.

\section{REFERENCES}

BARnes, R. (1954). Spec. Rep. Ser. med. Res. Coun.(Lond.) 282, 156.

CONTORNI, L. (1960). Minerva chir. 15, 268.

Cross, K. W. and Wilson, G. M. (1950). Clin. Sci. 9, 59.

Cudkowicz, L. and Armstrong, J. B. (1953). Brit. J. Tuberc. 47, 227.

EISINGER, A. J. (1968). Lancet ii, 518.

Flavell, G. (1956). Lancet i, 260.

Hall, G. H. (1959). Lancet i, 750 .

Killen, D. A., Foster, J. H., Govvel, W. G. Jnr., Stephenson, S. E., Jnr., Collins, H. A., Billings, F. T. and ScotT, H. W. Jnr. (1966). J. thorac. carciovasc. Surg. 51, 539.

MAUER, E. F. (1947). Amer. Heart J. 34, 852.

Mendlowitz, M. (1942). Medicine (Baltimore) 21, 269.

Parrote, J. C. (1964). Arch. Surg. 88, 661.

Reivich, M., Hollings, H. E., Roberts, B. and Toole, J. F. (1961). New Engl. J. Med. $265,878$.

RODGERS, R. E. (1941). Brit. 'med. J. ii, 439.

TuRner, R. H., Burch, E. G. and Sodeman, W. A. (1937). J. clin. Invest. 16, 789.

WILSON, G. M. (1952). Qd. I. Med. 45, 201. 